\title{
Improvement of Cardiac Function after Treatment with Octreotide followed by Trans-sphenoidal Surgery in an Acromegalic Patient who Presented with Congestive Heart Failure
}

\author{
Atsuhiro ShIMAKURA, ${ }^{1} \mathrm{MD}$, Hisatsugu MiYAKOSHI, ${ }^{1} \mathrm{MD}$, \\ Hitoshi OHKUWA, ${ }^{1}$ MD, Masahiro KITABAYASHI, ${ }^{2} \mathrm{MD}$, Toshio KOMAI, ${ }^{2} \mathrm{MD}$, \\ Azusa HISADA, ${ }^{1}$ Koichiro AOKI, ${ }^{1} \mathrm{MD}$, Satoru SAKAGAMI, ${ }^{3} \mathrm{MD}$, \\ Ken-ichi KoBAYASHI, ${ }^{3} \mathrm{MD}$, and Shigeo TAKATA, ${ }^{4} \mathrm{MD}$
}

\begin{abstract}
SUMMARY
Cardiovascular disease is a major cause of mortality and morbidity in patients with acromegaly. We describe the case of a 43-year-old man with acromegaly who presented with severe congestive heart failure. Treatment with the somatostatin analog octreotide improved cardiac function with an increase in left ventricular ejection fraction (LVEF) from $11 \%$ to $27 \%$. LVEF further increased to $43 \%$ after trans-sphenoidal surgery. Recovery was uneventful. We emphasize the need for early diagnosis and effective treatment of acromegaly to prevent cardiovascular complications. Octreotide therapy or trans-sphenoidal surgery, if possible, should be considered to control cardiac function even in acromegalic patients with severe congestive heart failure. (Jpn Heart J 2002; 43: 69-77)
\end{abstract}

Key words: Acromegaly, Congestive heart failure, Octreotide, Trans-sphenoidal surgery

ACROMEGALY is characterized by long-term hypersecretion of growth hormone (GH) with secondary elevation of tissue and plasma levels of insulin-like growth factor 1 (IGF-1). ${ }^{1)}$ Cardiovascular manifestations of acromegaly, including hypertension, arrhythmias, coronary artery disease, arteriosclerosis and congestive heart failure, are the major causes of morbidity and mortality in affected patients. $^{1-6)}$

We describe a patient with acromegaly who presented with severe congestive heart failure and exhibited marked improvement in cardiac function after treatment with octreotide followed by trans-sphenoidal surgery.

\footnotetext{
From ${ }^{1}$ Department of Internal Medicine and ${ }^{2}$ Department of Neurosurgery, Kouseiren Takaoka Hospital, Toyama, ${ }^{3}$ First Department of Internal Medicine, and ${ }^{4}$ Department of Health Science, School of Medicine, Kanazawa University, Ishikawa, Japan.

Address for correspondence: Atsuhiro Shimakura, MD, Department of Internal Medicine, Kouseiren Takaoka Hospital, 510 Eirakucho, Takaoka, Toyama 933-8555, Japan.

Received for publication April 13, 2001.

Revised and accepted August 3, 2001.
} 


\section{CAse Report}

The patient, a 43-year-old Japanese man, was admitted to our hospital because of nocturnal paroxysmal dyspnea (NYHA class III) in February 1999. He had undergone a splenectomy and left nephrectomy due to a traffic accident when he was 17 years old and partial gastrectomy due to gastric ulcers at the age of 23 . He had been diagnosed with hypertension at the age of 40, but had undergone no further examination or medical treatment. On admission, he was $172 \mathrm{~cm}$ tall and weighed $62 \mathrm{~kg}$. He had an irregular pulse of 96 beats $/ \mathrm{min}$, and his blood pressure was 138/76 mmHg. Auscultation revealed wheezing in bilateral lung fields, a high-pitched, grade II/VI holosystolic murmur, and an S3 gallop. The chest Xray revealed cardiomegaly (cardiothoracic ratio: 68\%) and pulmonary congestion (Figure 1). Sinus beats, premature ventricular contractions and left high voltage with ST-segment depression and T-wave changes were seen on the ECG (Figure 1). Echocardiography revealed an advanced dilated hypokinetic left ventricle ( 81 $\mathrm{mm}$ in end-diastole, $74 \mathrm{~mm}$ in end-systole, $9 \%$ fractional shortening) and diffuse, moderate hypertrophy associated with a dilated left atrium $(48 \mathrm{~mm})$ and pericardial effusion (Figure 2, Table). The diagnosis on admission was congestive heart failure and the patient was treated medically with digitalis $0.125 \mathrm{mg} /$ day, enala-

A

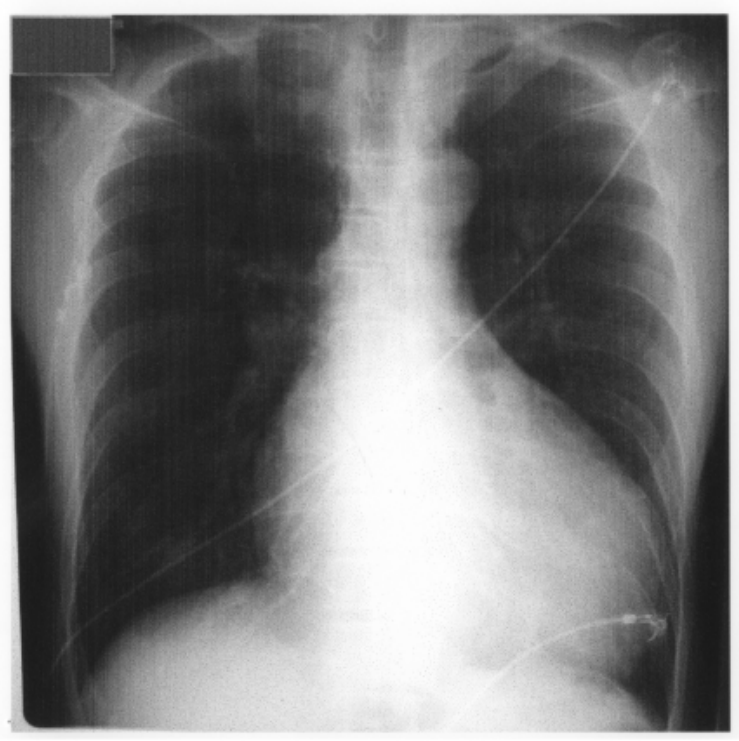

B

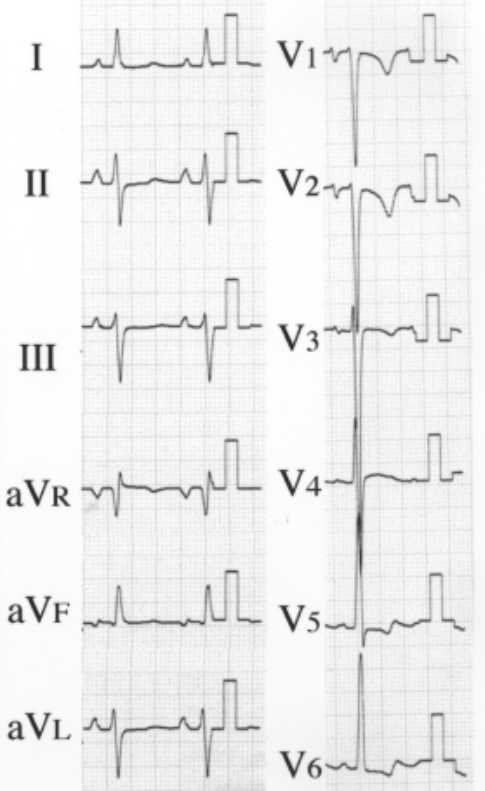

Figure 1. Chest X-ray on admission showing cardiac enlargement and pulonary congestion (left panel). The electrocardiogram recorded on admission demonstrated left ventricular hypertrophy (right panel). 
pril $5 \mathrm{mg} /$ day, furosemide $20 \mathrm{mg} /$ day, and dopamine $10 \mu \mathrm{g} / \mathrm{kg} / \mathrm{min}$. The next day, we realized that the patient also had an acromegalic face and acral enlargement (heel pad thickness $22 \mathrm{~mm}$ ). Serum levels of GH and IGF-1 were extremely high (77 ng/mL, $1460 \mathrm{ng} / \mathrm{mL}$, respectively, Table). The serum level of GH was not suppressed during the oral glucose tolerance test, and pituitary magnetic resonance imaging revealed a localized pituitary adenoma ( $7 \mathrm{~mm}$ in diameter) (Figure $3 \mathrm{~A})$. The diagnosis of acromegaly was thus established. At that time, radionuclide ventriculography revealed a severely hypokinetic left ventricle with an ejection fraction of $11 \%$ (Figure 4A). The plasma BNP level was $260 \mathrm{pg} / \mathrm{mL}$. Octreotide was given by subcutaneous injection at a dose of $300 \mu \mathrm{g} /$ day for two months beginning in February 1999. This treatment improved the GH level (28 $\mathrm{ng} / \mathrm{mL}$ ) and it also slightly improved cardiac symptoms and performance (LVEF increased to 27\%) (Figure 4B). Since the serum level of IGF-1 was still high $(1120 \mathrm{ng} / \mathrm{mL})$ and no further improvement of LVEF was observed by January 2000 (Figure 4C), the patient underwent trans-sphenoidal adenomectomy in March 2000. Histological examination of pituitary gland revealed eosinophilic cell adenoma (Figure 3B). The patient had an uneventful recovery and was asymptomatic for the next 4 months. Echocardiography revealed a dilated but restored hypokinetic left ventricle $(61 \mathrm{~mm}$ in end-diastole, $48 \mathrm{~mm}$ in end-systole, $21 \%$ fractional shortening) (Figure 5). On pulsed Doppler examination, peak transmitral inflow in early diastole (E) increased from $30 \mathrm{~cm} / \mathrm{sec}$ to $41 \mathrm{~cm} / \mathrm{sec}$ and peak transmitral inflow in atrial systole (A) increased from $38 \mathrm{~cm} / \mathrm{sec}$ to $42 \mathrm{~cm} /$
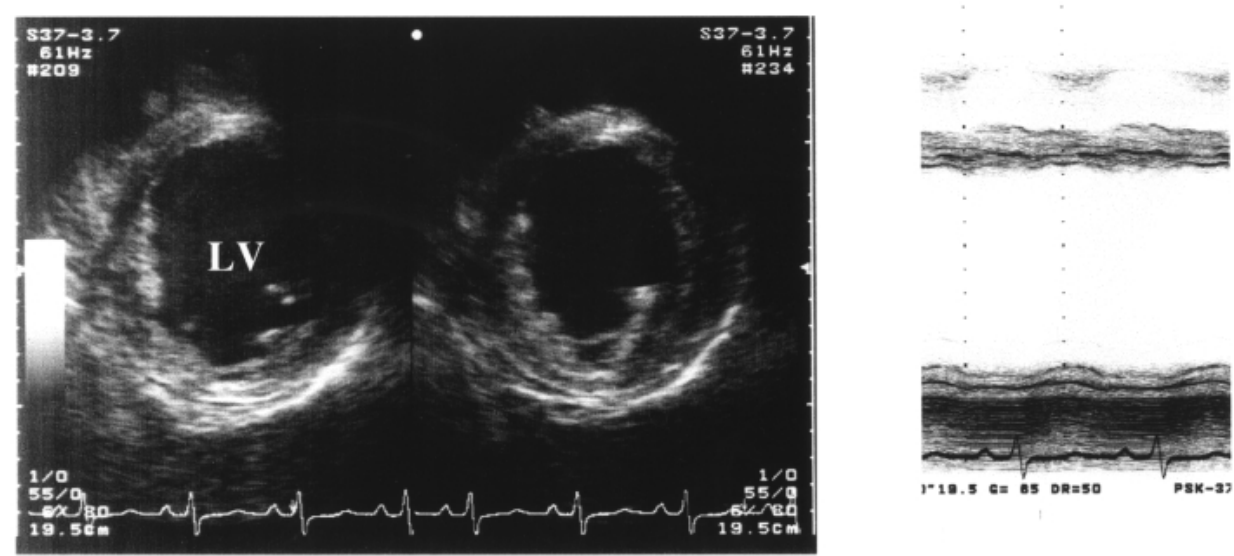

Diastole

Systole

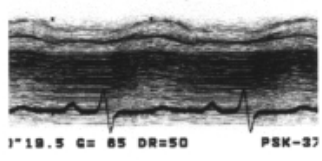

Figure 2. Parasternal short-axis echocardiography performed on admission, revealing a markedly dilated hypokinetic left ventricle and diffuse, moderate hypertrophy. $L V=$ left ventricle. 
Table. Time Course of Clinical and Cardiac Parameters, Hormonal Measurements, and Treatments

\begin{tabular}{|c|c|c|c|}
\hline & Baseline (February 1999) & $\begin{array}{l}\text { Two months after initia- } \\
\text { tion of octreotide ther- } \\
\text { apy (April 1999) }\end{array}$ & $\begin{array}{l}\text { Four months after trans- } \\
\text { sphenoidal surgery } \\
\text { (July 2000) }\end{array}$ \\
\hline \multicolumn{4}{|l|}{ Clinical parameters } \\
\hline Heart rate (beat/min) & 85 & 76 & 72 \\
\hline Systolic blood pressure (mmHg) & 122 & 120 & 116 \\
\hline Diastolic blood pressure (mmHg) & 64 & 66 & 58 \\
\hline \multicolumn{4}{|l|}{ Echocardiographic parameters } \\
\hline Left atrial dimension $(\mathrm{mm})$ & 48 & 47 & 43 \\
\hline LV-EDD $(\mathrm{mm})$ & 81 & 62 & 61 \\
\hline LV-ESD (mm) & 77 & 58 & 48 \\
\hline LV septal thickness (mm) & 18 & 18 & 18 \\
\hline LV posterior wall thickness (mm) & 17 & 16 & 16 \\
\hline $\mathrm{LV}$ mass $\left(\mathrm{gm} / \mathrm{m}^{2}\right)$ & 591 & 368 & 359 \\
\hline \multicolumn{4}{|c|}{ Pulsed Doppler parameters of LV inflow } \\
\hline E wave $(\mathrm{cm} / \mathrm{s})$ & 30 & 33 & 41 \\
\hline A wave $(\mathrm{cm} / \mathrm{s})$ & 38 & 37 & 42 \\
\hline E/A ratio & 0.79 & 0.89 & 0.98 \\
\hline \multicolumn{4}{|c|}{ Radionuclide left ventriculographic parameters } \\
\hline Ejection fraction $(\%)$ & 11 & 27 & 43 \\
\hline \multicolumn{4}{|l|}{ Hormonal measurements } \\
\hline $\mathrm{GH}(\mathrm{pg} / \mathrm{mL})(0.5>\mathrm{pg} / \mathrm{mL})$ & 77 & 28 & 4.8 \\
\hline IGF-1 (pg/mL) (106-398 pg/mL) & 1460 & 1120 & 1220 \\
\hline $\mathrm{BNP}(\mathrm{pg} / \mathrm{mL})$ & 260 & 48 & $8.0>$ \\
\hline \multicolumn{4}{|l|}{ Treatments } \\
\hline & Digitalis $0.125 \mathrm{mg} /$ day & Digitalis $0.125 \mathrm{mg} /$ day & Digitalis $0.125 \mathrm{mg} /$ day \\
\hline & Furosemide $20 \mathrm{mg} /$ day & Furosemide $20 \mathrm{mg} /$ day & Furosemide $20 \mathrm{mg} /$ day \\
\hline & Enalapril $5 \mathrm{mg} /$ day & Enalapril $5 \mathrm{mg} /$ day & Enalapril $5 \mathrm{mg} /$ day \\
\hline & ISDN $40 \mathrm{mg} / \mathrm{day}$ & ISDN $40 \mathrm{mg} /$ day & ISDN $40 \mathrm{mg} /$ day \\
\hline & Dopamine $5-10 \mu \mathrm{g} / \mathrm{kg} / \mathrm{min}$ & Octreotide $300 \mu \mathrm{g} /$ day & Octreotide; none \\
\hline
\end{tabular}

$\mathrm{LV}=$ left ventricular; $\mathrm{EDD}=$ end-diastolic dimension; $\mathrm{ESD}=$ end-systolic dimension; ISDN=Isosorbide dinitrate; GH=growth hormone; IGF-1=insulin-like growth factor; $\mathrm{BNP}=$ brain natriuretic peptide.

sec (Table). The serum GH level decreased by $4.8 \mathrm{ng} / \mathrm{mL}$, and radionuclide ventriculography revealed a moderately hypokinetic left ventricle with an ejection fraction of 43\% (Figure 4C). The plasma BNP level decreased to less than $8 \mathrm{pg} /$ $\mathrm{mL}$ (Table). Cardiac catheterization performed at that time revealed normal coronary angiographic findings, normal pulmonary wedge pressure (mean $8 \mathrm{mmHg}$ ), and a dilated, hypokinetic left ventricle. Histological examination of the right ventricle revealed myocardial hypertrophy with mild interstitial fibrosis and nuclear pleiomorphism (Figure 6). The patient was doing well when last seen as an outpatient in January 2001. 
A

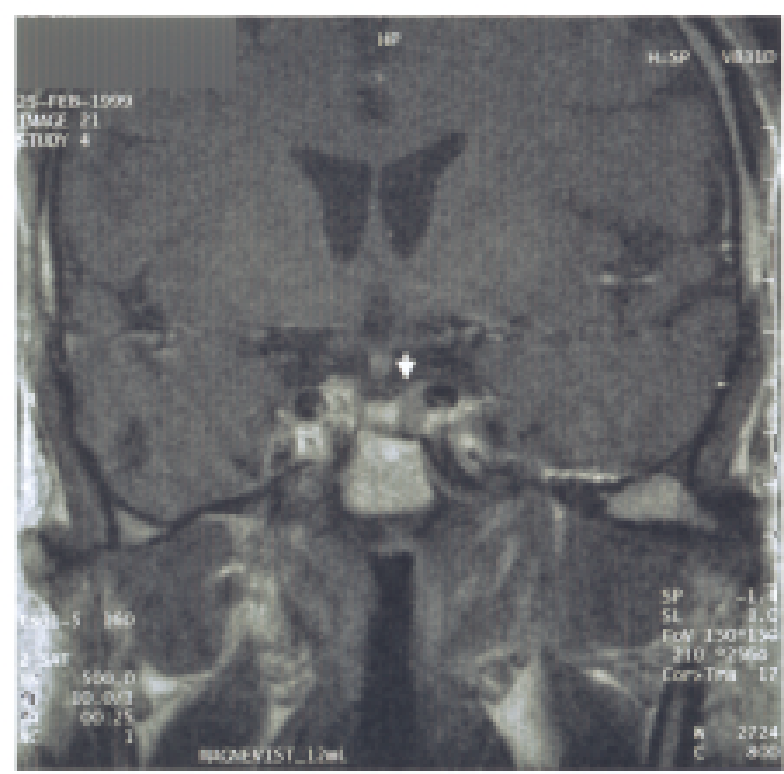

B

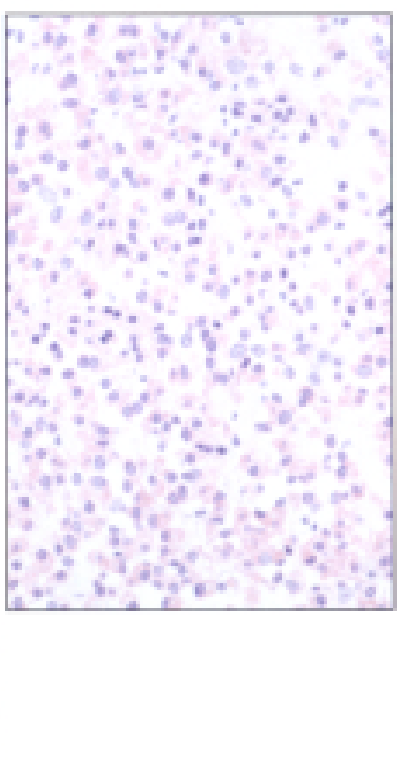

Figure 3. Magnetic resonance image revealing a localized pituitary adenoma ( $7 \mathrm{~mm}$ in diameter). Histological examination of the pituitary gland performed during trans-sphenoidal surgery revealed eosinophilic cell adenoma.

A

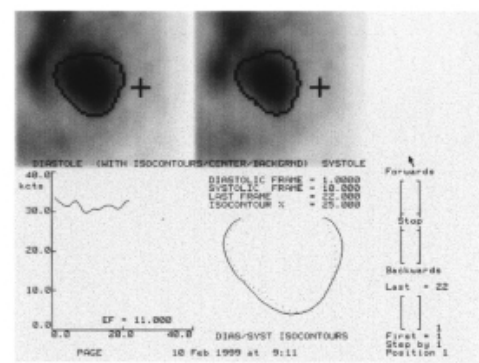

LVEF $=11 \%$

C

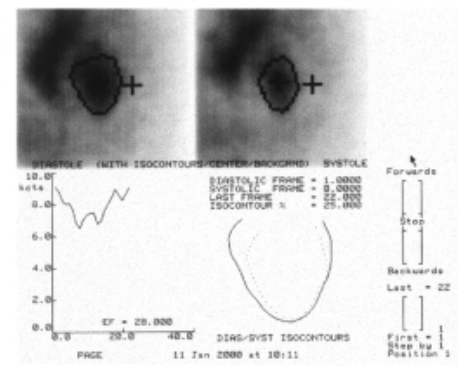

LVEF $=28 \%$
B

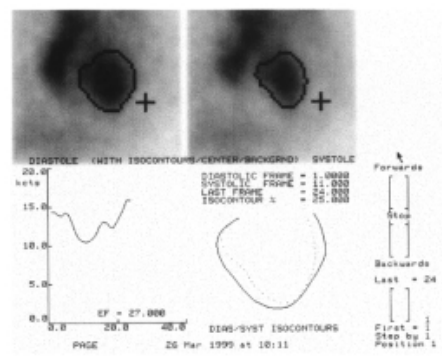

LVEF $=\mathbf{2 7} \%$

D

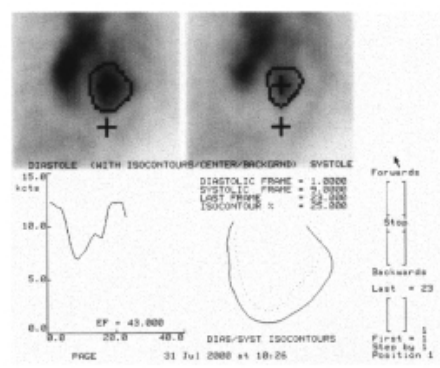

$\mathrm{LVEF}=\mathbf{4 3 \%}$

Figure 4. Radionuclide ventriculography revealing a severely hypokinetic left ventricle with an ejection fraction of $11 \%$ before octreotide therapy (panel A). Radionuclide ventriculography performed two months after initiation of octreotide therapy (panel B). Radionuclide ventriculography performed one year after initiation of octreotide therapy (panel C). Radionuclide ventriculography performed after trans-sphenoidal surgery (panel D). EF, ejection fraction. 

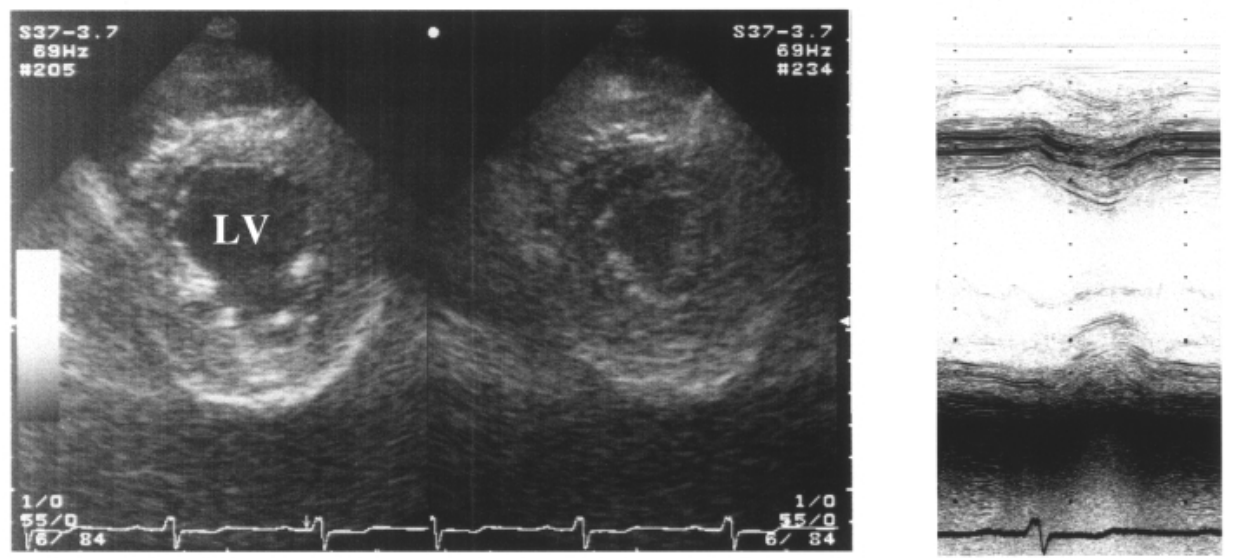

\section{Diastole}

\section{Systole}

Figure 5. Parasternal short-axis echocardiography performed after trans-sphenoidal surgery, revealing a dilated hypokinetic left ventricle with moderate hypertrophy. LV, left ventricle

$\mathbf{A}$

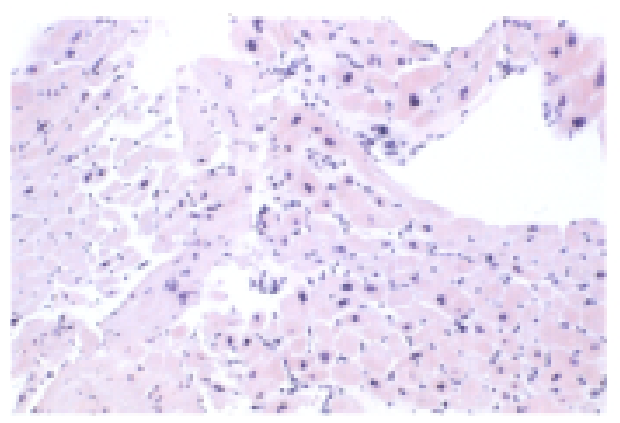

B

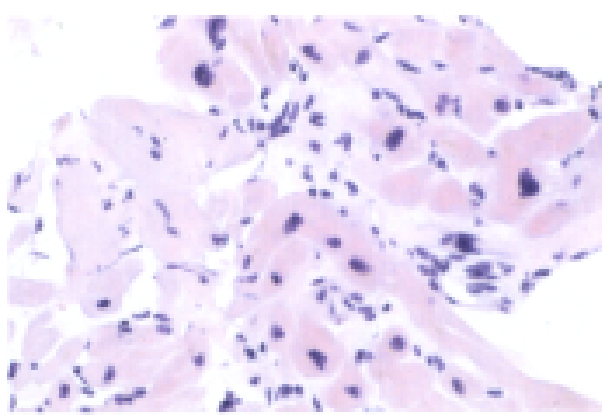

Figure 6. Histological examination of the right ventricle revealed myocardial hypertrophy with nuclear pleiomorphism. (A: low-power magnification, B: high-power magnification)

\section{DISCUSSION}

The following are crucial features of this case: 1) this acromegalic patient presented with severe congestive heart failure, 2) we administered the somatostatin analog octreotide even though the left ventricular ejection fraction was very low (11\%), and 3) octreotide improved cardiac function, but cardiac performance further improved after trans-sphenoidal surgery.

Patients with acromegaly present with various cardiac alterations, which can be responsible in part for their reduced life expectancy. ${ }^{1,45}$ Heart failure is estimated to occur in $10 \%$ to $20 \%$ of patients with acromegaly. ${ }^{1,6)}$ Some patients with 
acromegaly, even if without evidence of hypertension or atherosclerosis, have significant cardiac dysfunction, primarily cardiomegaly and congestive heart failure which are particularly resistant to conventional therapy. The degree of left ventricular hypertrophy is related to GH level, or the magnitude of decrease in $\mathrm{GH}^{7,8)}$ It has been suggested that a specific acromegalic cardiomyopathy exists as a distinct clinical entity. ${ }^{9}$. Cardiomyopathy develops progressively from an early stage, in which increased contractility and high cardiac output are detected, to a middle stage, in which concentric myocardial hypertrophy with interstitial fibrosis predominates. ${ }^{10-12)}$ The end-stage of acromegaly includes ventricular dilatation with total impaired performance and low cardiac output, although at present this event is extremely rare. ${ }^{13)}$

Octreotide is an eight amino acid cyclic peptide, and an analog of somatostatin, which inhibits the release of GH. ${ }^{14,15)}$ Somatostatin analogs have been shown to be effective in acromegalic patients, and in such patients suppression of circulating GH and IGF-1 through surgery or treatment with octreotide was followed by a significant decrease in cardiac size. ${ }^{16-19)}$ Chronic treatment with octreotide improved both left and right diastolic filling, left ventricular hypertrophy, hemodynamic responses, and cardiopulmonary performance during bicycle ergometry. ${ }^{8,19,20)}$ Treatment with somatostatin analogs has proved effective for acromegalics, even in those with advanced cardiac failure. ${ }^{17,21,22)}$ While others have observed worsening of congestive heart failure with octreotide, ${ }^{23,24)}$ Chanson, et al reported that a very low LVEF $(<20 \%)$ might increase the risk of precipitating cardiac failure with octreotide, since this somatostatin analog exerts a negative inotropic effect by decreasing $\mathrm{GH} .{ }^{25}$ )

In the present patient, left ventricular ejection fraction increased from $11 \%$ to $27 \%$ after treatment with octreotide, then it further increased to $43 \%$ after trans-sphenoidal surgery. It is possible that several direct or indirect effects of octreotide and surgery accounted for such an improvement.

Hypervolemia and a direct effect of growth hormone (or IGF-1) hypersecretion have been implicated in the pathogenesis of acromegalic cardiomyopathy. ${ }^{17)}$ Myocardial hypertrophy and interstitial fibrosis are common findings in acromegalic hearts, and, more rarely, there is myocarditis with lymphomonocytic infiltration. ${ }^{9)}$ In acromegalic heart disease, left ventricular filling changes are not due to the increase in LV mass per se, but to the irreversibility of LV after regression of hypertrophy. ${ }^{26)}$

Left ventricular mass and dilation decreased in our patient. An improvement in left ventricular diastolic function, as indicated by increases in the $\mathrm{E}$ wave and A wave of left ventricular inflow, and concomitant normalization of pulmonary capillary wedge pressure were observed after treatment. Moreover, the BNP concentration, which is related to left ventricular filling pressure and wall stress, ${ }^{27,28)}$ 
declined to levels well within the normal range after trans-sphenoidal surgery. These observations suggest an improvement in elasticity and an increase in early left ventricular filling. This view is supported by the finding of mild interstitial fibrosis, which is caused mainly by left ventricular filling dysfunction, ${ }^{9)}$ detected by histological examination after treatment.

Surgical treatment further improved cardiac function after treatment with octreotide therapy alone, although it had little effect on serum IGF-1 levels. The precise mechanism of this effect is unknown. It is possible that pituitary surgery precluded or reduced not only a release of growth hormone but also that of myotoxic agents other than GH and IGF-1. On the other hand, the incomplete normalization of GH and IGF-1 levels after pituitary surgery indicated that acromegaly was still biochemically active and that congestive heart failure could worsen or recur in the future. BNP-guided therapy ${ }^{28)}$ for congestive heart failure could be expected to reduce cardiac events in our patient.

In summary, cardiovascular disease is a major cause of mortality and morbidity in patients with acromegaly, and we therefore emphasize the need for early diagnosis and effective treatment of this disease. We have described here a patient with a striking clinical improvement in cardiac function after treatment with octreotide followed by trans-sphenoidal surgery.

\section{REFERENCES}

1. $\quad$ Melmed S. Acromegaly. N Engl J Med 1990; 322: 966-77.

2. McGuffin WL, Sherman BM, Roth J, et al. Acromegaly and cardiovascular disorders. Ann Int Med 1974; 81: 11-8.

3. Kahaly G, Olshausen KV, Kahaly SM, J, et al. Arrhythmia profile in acromegaly. Eur Heart J 1992; 13: 51-6.

4. Bates AS, Van't Hoff W, Jones JM, Clayton RN. Does treatment of acromegaly affect life expectancy? Metabolism (suppl 1) 1995; 44: 1-5.

5. Colao A, Merola B, Ferone D, Lombardi G. Extensive personal experience: Acromegaly. J Clin Endocrinol Metab 1997; 82: 2777-81.

6. Gordon H, Williams GH, Lilly LS, Seely EW. The heart in endocrine and nutrition disorders. In: Braunwald E, editor. Heart Disease: A Textbook of Cardiovascular Medicine, 5th ed. Philadelphia: WB Saunders, 1997: 1887-913.

7. Lim MJ, Barkan AL, Buda AJ. Rapid reduction of left ventricular hypertrophy in acromegaly after suppression of growth hormone hypersecretion. Ann Intern Med 1992; 117: 719-26.

8. Hradec J, Kral J, Janota T, Krsek M, Hana V, Marek J, et al. Regression of acromegalic left ventricular hypertrophy after lanreotide (a slow-release somatostatin analog). Am J Cardiol 1999; 83: 1506-9.

9. Lie JT, Grossman SJ. Pathology of the heart in acromegaly: Anatomic findings in 27 autopsied patients. Am Heart J 1980; 100: 41-52.

10. Lombardi G, Colao A, Marzullo P, Ferone D, Longobardi S, Esposito V, et al. Is growth hormone bad for your heart? Cardiovascular impact of GH deficiency and of acromegaly. J Endocrinol 1997; 155: s33-7.

11. Lombardi G, Colao A, Cuocolo A, Longobardi S, Di Somma C, Orio F. Cardiological aspects of growth hormone and insulin-like growth factor-1. J Pediatr Endocrinol Metab 1997; 10: 553-60.

12. Sacca L, Cittadini A, Fazio S. Growth hormone and the heart. Endocr Rev 1994; 15: 555-73. 
13. Colao A, Cuocolo A, Marzullo P, Nicolai E, Ferone D, Florimonte L, et al. Effects of 1-year treatment with octreotide on cardiac performance in patients with acromegaly. J Clin Endocrinol Metab 1999; 84: 17-23.

14. Reichlin S. Somatostatin. N Engl J Med 1983; 309: 1556-63.

15. Lamberts SWJ, Van Der Lely AJ, De Herder WW, Hofland LJ. Drug therapy: Octreotide. N Engl J Med 1996; 334: 246-54.

16. Thuesen L, Christenen SE, Weeke J, Orskov H, Henningsen P. The cardiovascular effects of octreotide treatment in acromegaly: An echocardiographic study. Clin Endocrinol (Oxf) 1989; 30: 619-25.

17. Chanson P, Timsit J, Masquet C, Warnet A, Guillausseau PJ, Birman P, et al. Cardiovascular effects of the somatostatin analog octreotide in acromegaly. Ann Int Med 1990; 113: 921-5.

18. Pereira JL, Rodriguez-Puras MJ, Leal-Cerro A, Martinez A, Garcia-Luna PP, Gavilan I, et al. Acromegalic cardiopathy improves after treatment with increasing doses of octreotide. J Endocrinol Invest 1991; 14: 17-23.

19. Merola B, Cittadini A, Colao A, Ferone D, Fazio S, Sabatini D, et al. Chronic treatment with the somatostatin analog octreotide improves cardiac abnormalities in acromegaly. J Clin Endocrinol Metab 1993; 77: 790-3.

20. Giustina A, Boni E, Romanelli G, Grassi V, Giustina G. Cardiopulmonary performance during exercise in acromegaly, and the effects of acute suppression of growth hormone hypersecretion with octreotide. Am J Cardiol 1995; 75: 1042-7.

21. Legrand V, Beckers A, Pham VT, Demoulin JC, Stevenaert A. Dramatic improvement of severe dilated cardiomyopathy in an acromegalic patient after treatment with octreotide and trans-sphenoidal surgery. Eur Heart J 1994; 15: 1286-9.

22. Chanson P, Timsit J, Masquet C, Guillausseau PJ, Warnet A, Lubetzki J. Heart failure responding to octreotide in patient with acromegaly. Lancet 1989; 1: 1263-4.

23. Leclercq F, Fille A, Albat B, Bringer J, Grolleau R, Jaffiol C. Congestive heart failure worsening with octreotide in acromegalic patients. Lancet 1991; 338: 1272-3.

24. Albat B, Leclercq F, Serre I, Fille A, Baldet P, Grolleau-Raoux R, et al. Heart transplantation for terminal congestive heart failure in an acromegalic patient. Eur Heart J 1993; 14: 1572-5.

25. Chanson P, Timsit J, Harris AG. Heart failure and octreotide in acromegaly. Lancet 1992; 339: 242-3.

26. Rossi E, Zuppi P, Pennestri F, Biasucci LM, Lombardo A, De Marinis L, et al. Acromegalic cardiomyopathy. Left ventricular filling and hypertrophy in active and surgically treated disease. Chest 1992; 102: 1204-8.

27. Richards AM, Crozier IG, Yandle TG, Espiner EA, Ikram H, Nicholls MG. Brain natriuretic factor: regional plasma concentrations and correlations with haemodynamic state in cardiac disease. Br Heart J 1993; 69: 4147 .

28. Troughton RW, Frampton CM, Yandle TG, Espiner EA, Nicholls MG, Richards AM. Treatment of heart failure guided by plasma aminoterminal brain natriuretic peptide (N-BNP) concentrations. Lancet 2000; 355: 1126-30. 